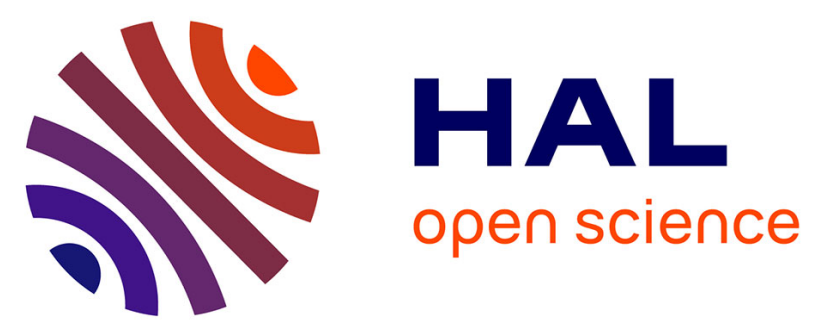

\title{
Autoimmune and inflammatory diseases associated with chronic myelomonocytic leukemia: A series of 26 cases and literature review
}

\author{
Eric Grignano, Arsene Mekinian, Thorsten Braun, Eric Liozon, Mohamed \\ Hamidou, Olivier Decaux, Xavier Puechal, Jean-Emmanuel Kahn, Yoland \\ Schoindre, Julien Rossignol, et al.
}

\section{To cite this version:}

Eric Grignano, Arsene Mekinian, Thorsten Braun, Eric Liozon, Mohamed Hamidou, et al.. Autoimmune and inflammatory diseases associated with chronic myelomonocytic leukemia: A series of 26 cases and literature review. Leukemia Research, 2016, 47, pp.136-141. 10.1016/j.leukres.2016.05.013 . hal-01388084

\section{HAL Id: hal-01388084 https://hal.science/hal-01388084}

Submitted on 7 Feb 2017

HAL is a multi-disciplinary open access archive for the deposit and dissemination of scientific research documents, whether they are published or not. The documents may come from teaching and research institutions in France or abroad, or from public or private research centers.
L'archive ouverte pluridisciplinaire HAL, est destinée au dépôt et à la diffusion de documents scientifiques de niveau recherche, publiés ou non, émanant des établissements d'enseignement et de recherche français ou étrangers, des laboratoires publics ou privés. 


\section{Autoimmune and inflammatory diseases associated with chronic myelomonocytic leukemia: A series of 26 cases and literature review}

Eric Grignano ${ }^{1 *}$, Arsene Mekinian ${ }^{1 *}$, Thorsten Braun ${ }^{2}$, Eric Liozon ${ }^{3}$, Mohamed Hamidou ${ }^{4}$ Olivier Decaux ${ }^{5}$, Xavier Puéchal ${ }^{6}$, Jean Emmanuel Kahn" ${ }^{7}$ Yoland Schoindre', Julien Rossignol $^{8}$, Olivier Lortholary ${ }^{9}$, Bertrand Lioger ${ }^{10}$, Olivier Hermine ${ }^{8}$, Sophie Park ${ }^{11}$, Lionel Ades $^{13}$, François Montestruc ${ }^{12}$, Laure Ricard ${ }^{1}$, Claude Gardin ${ }^{2}$, Pierre Fenaux ${ }^{13^{* *}}$, Olivier Fain $^{1{ }^{* *}}$, on behalf of GFM, SNFMI and CRI

${ }^{1}$ DHUi2B, Service de Médecine Interne, Hôpital Saint Antoine, APHP, Université Paris 6, 75012 Paris, France.

${ }^{2}$ Service d’hématologie clinique, Université Paris 13, AP-HP, Avicenne, 93000, Bobigny, France.

${ }^{3}$ Service de médecine interne, CHU Dupuytren, Limoges, France

${ }^{4}$ Service de médecine interne, Université Nantes, CHU de Nantes, Nantes, France

${ }^{5}$ Service de médecine interne, Université Rennes 1, Hôpital Universitaire de Rennes, Rennes, France

${ }^{6}$ Service de médecine interne, Université Paris 5, AP-HP, CHU Cochin, Paris, France

${ }^{7}$ Service de médecine interne, Université Versailles-Saint Quentin en Yvelines, Hôpital Foch, Suresnes, France

${ }^{8}$ Service d’hématologie clinique, Université Paris 5, AP-HP, Hôpital Necker, Paris, France

${ }^{9}$ Service de maladies infectieuses, Université Paris 5, AP-HP, Hôpital Necker, Paris, France

${ }^{10}$ Service de médecine interne, CHU Tours, Tours, France

${ }^{11}$ Service d'hématologie clinique, CHU Grenoble, Grenoble, France.

${ }^{12}$ eXYSTAT, Statistics, Malakoff, France

${ }^{13}$ Service d'hématologie clinique, Université Paris 7, AP-HP, CHU Saint-Louis, Paris, France *Both authors equally contributed to this work

** Both authors equally contributed to this work

Correspondance and reprint request to: Arsène Mekinian, Service de Médecine Interne, Université Paris 6, AP-HP, Hôpital Saint Antoine, Paris, 75012. France

E-mail: arsene.mekinian@sat.aphp.fr

\section{Highlights}

Vasculitis are the most frequent autoimmune diseases associated with CMML

CMML features are worse when associated to SAIDs

Hypomethylating agents may represent an alternative therapy after steroids.

\section{Abstract}

We wanted to describe the characteristics, treatment and outcome of autoimmune and inflammatory diseases (SAIDs) associated with chronic myelomonocytic leukemia (CMML), and conducted a French multicenter retrospective study and a literature review. 
We included 26 cases of CMML (median age 75 years, 54\% female), 80\% with CMML-1. CPSS score was low ( 0 or 1 ) in $75 \%$ of cases. SAIDS was systemic vasculitis in $54 \%$. Diagnosis of the 2 diseases was concomitant in 31\% cases, and CMML was diagnosed before SAIDs in 12 cases (46\%). First line treatment for SAIDs consisted mostly of steroid, with $85 \%$ of response. Second-line treatment was needed in $40 \%$ cases. Six patients received hypomethylating agents, with $66 \%$ response on SAIDs. A literature review found 49 cases of CMML-associated SAIDs, in whom SAIDs was systemic vasculitis in $29 \%$ cases.

Hence, vasculitis is the most frequent SAIDs associated with CMML. After initial response to steroids, recurrence and steroid-dependence were frequent. Hypomethylating agents may be interesting in this context.

Keywords: chronic myelomonocytic leukemia; autoimmune diseases; vasculitis; immunosuppressive agents ; hypomethylating agents ; outcome

\section{INTRODUCTION}

Chronic myelomonocytic leukemia (CMML) is the most frequent subtype of the WHO 2008 classification defined group of myelodysplastic syndrome/myeloproliferative neoplasms (MDS/MPN). The disease is characterized by persistent monocytosis and variable features of myeloproliferative (high white blood cell [WBC] count and splenomegaly) and myelodysplastic features (anemia, thrombocytopenia and excess marrow blasts)(1).

Systemic autoimmune and/or inflammatory diseases (SSAIDs) have been reported in $15 \%$ to 25\% of MDS/CMML patients, in series that included only few CMML cases, without focus on this disorder (2). In a recent report, we described 123 patients with MDS/CMMLassociated SAIDs, mainly systemic vasculitis (32\%), connective tissue diseases (25\%) and inflammatory arthritis (23\%)(3). The type of MDS/CMML was refractory anemia in $25 \%$ of cases, refractory anemia with blasts excess-1 in 15\% and CMML in 15\%.

Studies specifically analyzing CMML with SAIDs are lacking, as are data for SAIDs treatment response and outcome in those patients. Here we describe 26 cases of CMML with SAIDs (including 7 new cases), compare these cases to CMML without SAIDs, and report the literature review of CMML with SAIDs.

\section{PATIENTS AND METHODS}

\section{Patients' selection}

Case reports of patients with both CMML and SAIDs from 1993 to 2013 were collected retrospectively from 15 departments of hematology and internal medicine in France by using questionnaires submitted to members of the "Société Francaise de Médecine Interne" and the "Club Rhumatisme et Inflammation". Inclusion criteria were CMML diagnosis according to the 2008 WHO classification (persistent monocytosis $>1 \mathrm{G} / \mathrm{L}$, without any evidence of infection, absence of BCR-ABL and/or PDGFR $\alpha$ mutations, marrow blasts $<20 \%$ ) and one of dysplasia of at least one cell line, or evidence of a clonal genetic or molecular mutation). We excluded cases with a $>5$-year interval between diagnosis of CMML and SAIDs, patients with immunosuppressive treatment $>12$ months before CMML diagnosis, or who experienced infectious or drug-induced SAIDs. 


\section{CMML prognostic score and response assessment}

The CMML-Specific Prognostic Scoring System (CPSS) was used to retrospectively classify cases by 4 prognostic categories: low, intermediate-1, intermediate-2 and high (1). Response of CMML to treatment was retrospectively defined by recently proposed response criteria for MPN/MDS (4).

\section{SAIDs definition}

SAIDs (incomplete/incomplete forms) were diagnosed and classified by using international diagnostic criteria for each SAIDs type (1996 American College of Rheumatology for systemic lupus erythematosus, Chapel Hill classification for systemic vasculitis, etc.). Steroid dependence was defined as a daily equivalent prednisone amount $\geq 20 \mathrm{mg}$ at least during 2 months which could not be decreased because of SAIDs (at diagnosis of SAIDs and any time when the steroid were needed for SAIDs).

\section{CMML patients without SAIDs}

We selected a control group of 103 CMML patients without any autoimmune/inflammatory features followed prospectively from 2003 to 2013 in the hematology department of Hôpital Avicenne (Paris 13 University), and included in the registry of the "Groupe Francophone des Myélodysplasies” (GFM).

\section{Literature review: search strategy}

Two investigators (AM and EG) searched for articles in MEDLINE via PubMed (January 1989 to August 2015) with the keywords "chronic myelomonocytic leukemia", "arthritis", "vasculitis", "connective tissue disease”, "autoimmune disease”, "paraneoplastic syndrome”. The literature search yielded 14 citations (5-13). Five reports were excluded because of incomplete data concerning SAIDs features.

\section{Statistical analysis}

Sample size

The primary objective of the study is to estimate the prevalence of SAIDs in a population of patients with CMML. For an expected prevalence of 20\%, 126 CMML are required for an accuracy of $7 \%$. With 126 patients, the 95\% two-sided confidence interval of a $20 \%$ prevalence is expected to be [13\%; $27 \%]$. With this sample size, a two group chi square test with a $5 \%$ two-sided significance level will have $80 \%$ power to detect the difference between a CMML patients with SAIDs and CMML patients without SAIDs with and odd ratio at 0.2 (corresponding to proportions of 10\% in CMML patients with SAIDs and 25\% in CMML patients without SAIDs).

Data were described with mean \pm SD and/or median (ranges) for continuous variables and number with frequencies (\%) for categorical variables. To account for missing data, results were expressed as observed data (missing data not replaced). Fisher's exact or chi-square test were used to compare categorical variables and Student's $t$ or Kruskall Willis test for continuous variables. Overall survival was defined from the duration between diagnosis of 
CMML and last available visit or death. Time to event data was analysed with Kaplan Meier methodology and associated log-rank test. Statistical analyses involved use of SAS 9.4 (SAS Inst., Cary, NC). $\mathrm{p}<0.05$ was considered statistically significant.

\section{RESULTS}

\section{CMML and SAIDs characteristics}

Twenty six patients with CMML and SAIDs (median age 75 years [range 16-82]; M/F ratio 12/14) were included with 21 CMML-1 (81\%) and 5 CMML-2 (Table 1). At CMML diagnosis, median monocytes count was 3000/mm3 [range 160-10000/mm3] and proportion of marrow blasts $4 \%$ [range $0-20 \%$ ]. CPSS score was $0(n=6,37.5 \%), 1(n=6,37.5 \%), 2$ or 3 $(n=3,19 \%)$, and $4(n=1,6 \%)$ (Table 1). According to the French-American-British classification of CMML, 55\% of patients had a myelodysplastic form (WBC $<13000 / \mathrm{mm}^{3}$ ) and $45 \%$ a myeloproliferative form (WBC $>13000 / \mathrm{mm}^{3}$ ).

The type of SAIDs was systemic vasculitis $(n=14,54 \%$, including polyarteritis nodosa $(n=6)$, connective-tissue disease $(n=2,8 \%)$, inflammatory arthritis $(n=4,15 \%)$ (polymyalgia rheumatica, $n=2$; undifferentiated arthritis, $n=2)$., neutrophilic dermatosis $(n=2,8 \%)$, retroperitoneal fibrosis $(n=1)$, immune thrombocytopenia $(n=1)$ and unclassified forms $(n=2$, 8\%) (Supplementary Table 1). Connective tissue diseases consisted of relapsing polychondritis $(\mathrm{n}=1)$ and Sjögren's syndrome $(\mathrm{n}=1)$.

Median interval between diagnosis of SAIDs and CMML was 0.5 months [range 0-44]. Diagnosis of the 2 diseases was concomitant in 8 cases (35\%), diagnosis of CMML preceded SAIDs in 12 cases (46\%) and followed diagnosis of SAIDs in 6 (23\%).

\section{Comparison between CMML with and without SAIDs}

Compared with the 103 CMML patients without SAIDs included in the GFM registry, CMML with SAIDs were younger (median age 75 vs 79 years; $p<0.01$ Student test), more frequently had CMML-2 (19\% vs 7\%, p =0.06 Fisher test), a greater percentage of marrow blasts (median 4\% vs $2 \%$, mean (std) 3.2 (4.9) versus 6.7 (6.1) $\mathrm{p}<0.01$ Student test) and greater incidence of poor karyotype, including trisomy 8 , abnormalities of chromosome 7 or complex karyotype ( $15 \%$ vs $2 \%$, $\mathrm{p}=0.04$ Fisher test); however, the relative frequency of CPSS categories did not differ between the 2 groups ( $\mathrm{p}=0.43$ Fisher test) (Table 1).

\section{CMML and SAIDs treatments and outcomes}

In the 26 patients with CMML and SAIDs, frontline hematological treatment was used in 15 cases $(58 \%)$ and consisting of azacytidine $(\mathrm{n}=2)$ and hydroxyurea $(\mathrm{n}=13)$. SAIDs were treated in 25 cases, including steroids in 24, with a median daily prednisone dose of $32.5 \mathrm{mg} / \mathrm{day}$, associated with immunosuppressive drugs in 2 cases (cyclophosphamide). One patient with unclassified disease received colchicine alone. Overall, 20/23 cases with available data (87\%) showed complete $(n=15)$ or partial SAIDs response, including $17(74 \%)$ treated with steroids alone. Second-line treatment was needed in 10 cases $(40 \%)$ because of SAIDs relapse $(n=5)$, steroid dependence $(n=4)$ or non-response $(n=1)$; and $6 / 8$ cases $(75 \%)$ showed SAIDs response after second-line treatment, including 4 complete responses (Figure 1).

Of 14 patients with vasculitis, 12 received first-line treatment with steroids, associated with cyclophosphamide in 1 patient. The last patient with pseudo-Behcet disease received 
anakinra. Twelve of the 13 cases (92\%) showed complete $(\mathrm{n}=7)$ or partial SAIDS response. Second-line treatment was needed in 7 cases $(54 \%)$ because of SAIDs relapse $(n=3)$, steroid dependence $(n=3)$ or non-response $(n=1) ; 6 / 7$ cases $(86 \%)$ showed SAIDs response after second-line treatment, including complete responses in 2 cases.

SAIDs outcome and treatment responses were not correlated with CMML baseline hematological characteristics. Among 15 patients treated for CMML (hydroxyurea in 13 cases and azacytidine or decitabine in 6 cases, 4 patients with both hydroxyurea and hypomethylating agents), 8/13 patients with sufficient data have SAIDs remission and no SAIDs remission in $5 / 13$ cases $(\mathrm{p}=0.4)$. Among our 6 cases treated with 5 -azacytidine or decitabine, 4 showed SAIDs remission at the last follow-up associated with hematological response.

During the follow-up (median 30.7 months [range 14.5-61.9]), the number of involved organs and C-reactive protein levels significantly decreased (from 3 to 1 and 87 to $9 \mathrm{mg} / \mathrm{l}$, respectively), as did the prednisone daily amount (37 mg/day at diagnosis to $19 \mathrm{mg} / \mathrm{day}$ at the last visit) (supplementary Table 3).

\section{Patient outcome}

Acute myeloid leukemia developed in 26\% of CMML patients with SAIDs, compared with $16 \%$ of the CMML without SAIDs ( $\mathrm{p}=0.17$ Fisher test).

We observed 4 deaths in the CMML with SAIDs group and 25 in the CMML without SAIDs group. Survival rates at 1 and 5 years were 95\% (95\% CI 70-99) and 78\% (44-93) in CMML with SAIDs, and 87\% (77-93) and 50\% (32-66) in CMML without SAIDs. Median overall survival was 58 months in patients without SAIDs and not reached (greater than 72 months) in patients with SAIDs (p=0.07 Log-rank test), with Hazard ratio estimated to 2.6 [0.9; 7.5].

\section{Literature review}

A literature review revealed 49 cases of CMML with SAIDs. Their median age was 67.7 years; $65 \%$ were males (Table 3). In patients with available data, 24\% had proliferative CMML (WBC count > 13 g/L), 8\% CMML-2 and 35\% abnormal karyotype, including 17\% complex karyotypes. SAIDs were systemic vasculitis in $26.5 \%$ (polyarteritis nodosa in $16 \%$ ), connective-tissue disease in $2 \%$, inflammatory arthritis in $8 \%$, and autoimmune thrombocytopenia in 32.5\%. Diagnosis of the 2 diseases was concomitant in 25\%; diagnosis of CMML preceded that of SAIDs in 37.5\% and occurred after SAIDs in 37.5\%. Treatment of SAIDs consisted of steroids in $80 \%$ of cases, with first-line response obtained in $76 \%$. Second-line treatment was needed in $64 \%$ of the cases (including cyclophosphamide in 8 patients; VP16 in 3; romiplostin, in 3). Overall, 78\% of patients achieved remission of SAIDs (complete response in $45 \%$ ), including $72 \%$ of patients with vasculitis. Acute myeloid leukemia developed in $12 \%$ of the patients.

\section{Discussion}

In this largest series of CMML-related SAIDs to our knowledge, we found that systemic vasculitis was the most frequent SAIDs associated with CMML, with higher prevalence of 
systemic vasculitis, mostly periateritis nodosa. Previous studies described SAIDs in patients with MDS, but CMML was rarely included $(7,8,14,15)$. Only one series of 8 cases of medium-vessel vasculitis associated with CMML was reported, with SAIDs diagnosed after CMML, and a fatal course in 7 cases (7). Overall good response to first line treatment was showed (87\%), even mostly steroid dependence and relapse needed retreatment.

The clinical SAIDs associated with CMML could be as various as systemic vasculitis, connective tissue diseases and ITP. Even the frequencies are different from various case series, as $26 \%$ of ITP in recent study by Peker et al, and 3.5\% in our study, the various inclusion criteria could explain this differences and prospective studies are needed to determine the real prevalence of SAIDs associated with CMML. As compared with CMML without SAIDs, our CMML patients with SAIDs showed unfavorable CMML features: more frequently CMML-2, poor karyotype and greater proportion of medullar blasts. No previous study has focused on survival of patients with CMML-associated SAIDs, and the impact of the SAIDs on survival remains controversial $(16,17)$. Several reports showed that in patients with various SAIDs types, survival was similar in comparison with MDS without SAIDs.(14) Even the presence of vasculitis could be associated with poor outcome; (15) in a 4-year prospective study, only IPSS score was relevant for MDS prognosis(9). In our large series of 123 patients with MDS-associated SAIDs, survival did not differ from that in 665 patients with MDS without SAIDs(3).; The limited number of patients and deaths events in CMMLSAIDs group, the difference in patients age between CMML with and without SAIDs did not allow us to have definite conclusion whether the presence of SAIDs could affect the overall survival.

Response to SAIDs specific treatment, mostly steroids alone, was obtained in $87 \%$ of cases. No previous studies focused on CMML-associated SAIDs treatment and outcomes, and response rates to steroids alone was similar comparing to our larger cohort of MDS-associated SAIDs (80\%)(3). Despite this initial good response, $40 \%$ of patients needed a second-line treatment for relapse or steroid dependence, comparing to $48 \%$ in other MDS-associated SAIDs (3). The effect of MDS treatment on SAIDs outcome is not established, and few casereports described SAIDs remission with hypomethylating agents(18-20). Among our 6 cases treated with 5-azacytidine or decitabine, 4 showed SAIDs remission associated with hematological response. In $20 \mathrm{MDS} / \mathrm{CMML}$ patients with steroid-refractory or dependent SAIDs, we recently showed a $80 \%$ overall response with 5-azacytidine, with significantly decreased steroid amounts and steroid dependence rates, suggesting a potential interest for HMAs in this context(21).

\section{Conclusion}

In this case-series of CMML-associated SAIDs, various diseases could be associated with CMML, mostly vasculitis and immune thrombocytopenia. Even though SAIDs was usually responsive to steroids, recurrence and steroid-dependence indicate the need to determine a better treatment strategy and the value of CMML-specific treatment for SAIDs remission.

\section{Conflicts of interest and funding: none.}




\section{Acknowledgements}

We thank the French National Society of Internal Medicine, the Club Rhumatismes et Inflammation and the Groupe Francophone des Myélodysplasies for their help in the organization of this study. We thank Catherine Henry (Service de cytogénétique, CHU de Rennes, Rennes) for help in characterizing bone-marrow karyotypes for some cases.

\section{Authors contribution}

All authors were involved in drafting the article. Olivier Fain had full access to all of the data in the study and takes responsibility for the integrity of the data and the accuracy of the data analysis.

${ }^{3}$ Study conception and design. AM, TB, PF, OF.

Acquisition of data. AM, TB, EL, MH, OD, XP, JEK, YS, JR, OL, BL, OH, SP, LA, FM, CG, PF, OF.

Analysis and interpretation of data. MA, FM, TB, PF, OF.

\section{Conflicts of interest: none.}

All authors had access to the data and play a role in writing the manuscript.

\section{Acknowledgements}

We thank the French National Society of Internal Medicine, the Club Rhumatismes et Inflammation and the Groupe Francophone des Myélodysplasies for their help in the organization of this study. We thank Catherine Henry (Service de cytogénétique, CHU de Rennes, Rennes) for help in characterizing bone-marrow karyotypes for some cases.

\section{References}

1. Such E, Germing U, Malcovati L, Cervera J, Kuendgen A, Della Porta MG, et al. Development and validation of a prognostic scoring system for patients with chronic myelomonocytic leukemia. Blood. 2013 Apr 11;121(15):3005-15.

2. Berthier S, Magy N, Gil H, Schneider MB, Vuitton DA, Dupond JL. [Myelodysplasias and systemic diseases. A non-fortuitous association]. Rev Med Interne. 2001 May;22(5):428-32.

3. Mekinian A, Grignano E, Braun T, Decaux O, Liozon E, Costedoat-Chalumeau N, et al. Systemic inflammatory and autoimmune manifestations associated with myelodysplastic 
syndromes and chronic myelomonocytic leukaemia: a French multicentre retrospective study. Rheumatol Oxf Engl. 2015 Sep 8;

4. Savona MR, Malcovati L, Komrokji R, Tiu RV, Mughal TI, Orazi A, et al. An international consortium proposal of uniform response criteria for myelodysplastic/myeloproliferative neoplasms (MDS/MPN) in adults. Blood. 2015 Mar 19;125(12):1857-65.

5. Smail A, Ducroix JP, Sahir R, Lorette F, Desablens B, Sevestre H, et al. [Wegener's disease and myelomonocytic leukemia: a fortuitous association?]. Rev Médecine Interne Fondée Par Société Natl Francaise Médecine Interne. 1989 Oct;10(5):463-5.

6. Leung AC, McLay A, Boulton-Jones JM. Polyarteritis nodosa and monocytic leukaemia. Postgrad Med J. 1986 Jan;62(723):35-7.

7. Hamidou MA, Boumalassa A, Larroche C, Kouri DE, Blétry O, Grolleau J-Y. Systemic medium-sized vessel vasculitis associated with chronic myelomonocytic leukemia. Semin Arthritis Rheum. 2001 Oct;31(2):119-26.

8. Saif MW, Hopkins JL, Gore SD. Autoimmune phenomena in patients with myelodysplastic syndromes and chronic myelomonocytic leukemia. Leuk Lymphoma. 2002 Nov;43(11):2083-92.

9. Giannouli S, Voulgarelis M, Zintzaras E, Tzioufas AG, Moutsopoulos HM. Autoimmune phenomena in myelodysplastic syndromes: a 4-yr prospective study. Rheumatol Oxf. 2004 May;43(5):626-32.

10. Isoda A, Sakurai A, Ogawa Y, Miyazawa Y, Saito A, Matsumoto M, et al. Chronic inflammatory demyelinating polyneuropathy accompanied by chronic myelomonocytic leukemia: possible pathogenesis of autoimmunity in myelodysplastic syndrome. Int J Hematol. 2009 Sep;90(2):239-42.

11. Park JK, Gelber AC, Zheng G, McDevitt MA, Gocke CD, Baer AN. Large-vessel vasculitis as an early manifestation of chronic myelomonocytic leukemia. J Clin Oncol Off J Am Soc Clin Oncol. 2011 Jul 10;29(20):e601-3.

12. Hadjadj J, Michel M, Chauveheid M-P, Godeau B, Papo T, Sacre K. Immune thrombocytopenia in chronic myelomonocytic leukemia. Eur J Haematol. 2014 Dec;93(6):521-6.

13. Peker D, Padron E, Bennett JM, Zhang X, Horna P, Epling-Burnette PK, et al. A close association of autoimmune-mediated processes and autoimmune disorders with chronic myelomonocytic leukemia: observation from a single institution. Acta Haematol. 2015;133(2):249-56.

14. de Hollanda A, Beucher A, Henrion D, Ghali A, Lavigne C, Levesque H, et al. Systemic and immune manifestations in myelodysplasia: a multicenter retrospective study.

Arthritis Care Res Hoboken. 2011 Aug;63(8):1188-94.

15. Fain O, Hamidou M, Cacoub P, Godeau B, Wechsler B, Paries J, et al. Vasculitides associated with malignancies: analysis of sixty patients. Arthritis Rheum. 2007 Dec 15;57(8):1473-80. 
16. Enright H, Miller W. Autoimmune phenomena in patients with myelodysplastic syndromes. Leuk Lymphoma. 1997 Feb;24(5-6):483-9.

17. Okamoto T, Okada M, Mori A, Saheki K, Takatsuka H, Wada H, et al. Correlation between immunological abnormalities and prognosis in myelodysplastic syndrome patients. Int J Hematol. 1997 Oct;66(3):345-51.

18. Pilorge S, Doleris LM, Dreyfus F, Park S. The autoimmune manifestations associated with myelodysplastic syndrome respond to 5-azacytidine: a report on three cases. Br J Haematol. 2011;153(5):664-5.

19. Frietsch JJ, Dornaus S, Neumann T, Scholl S, Schmidt V, Kunert C, et al. Paraneoplastic inflammation in myelodysplastic syndrome or bone marrow failure: case series with focus on 5-azacytidine and literature review. Eur J Haematol. 2014 Sep;93(3):247-59.

20. Tanaka H, Shimizu N, Tougasaki E, Kawajiri C, Hashimoto S, Takeda Y, et al. Successful treatment by azacitidine therapy of intestinal Behçet's disease associated with myelodysplastic syndrome. Int J Hematol. 2013 Apr;97(4):520-4.

21. Fraison J-B, Mekinian A, Grignano E, Kahn J-E, Arlet J-B, Decaux O, et al. Efficacy of Azacitidine in autoimmune and inflammatory disorders associated with myelodysplastic syndromes and chronic myelomonocytic leukemia. Leuk Res. 2016 Apr;43:13-7.

Figure 1. AIDs treatments and response.

1st line treatment

$\mathrm{N}=\mathbf{2 4}$

$2 d$ line treatment

$\mathrm{N}=10$

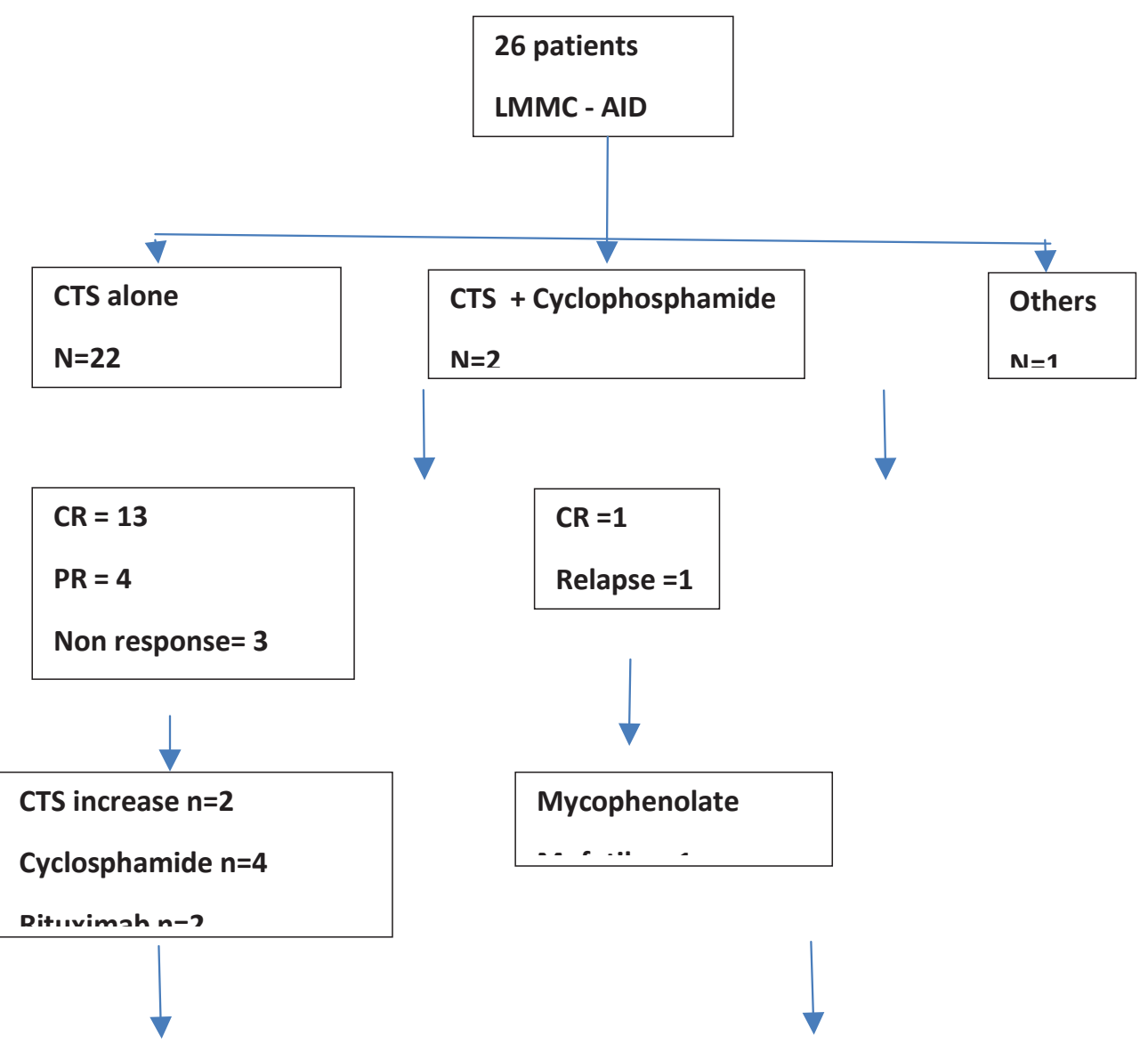


3d line treatment

$\mathbf{N}=\mathbf{2}$

$$
\mathrm{CR}=4
$$

$\mathrm{PR}=\mathbf{2}$

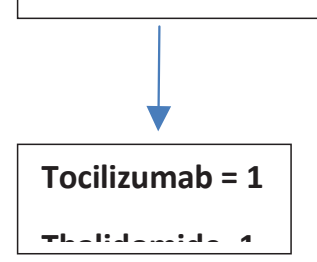

$\mathrm{CR}=1$

Non resnonse $=1$

$\mathrm{CR}=$ complete response; $\mathrm{PR}$ = partial response; $\mathrm{CTS}$ = corticosteroids

Table 1. Characteristics of chronic myelomonocytic leukemia (CMML) in patients with and without autoimmune and inflammatory diseases (SAIDs).

\begin{tabular}{|c|c|c|c|}
\hline & With SAIDs & Without SAIDs & $P$ value \\
\hline $\begin{array}{l}\text { CMML subtype } \\
\qquad \begin{array}{r}\text { CMML } 1 \\
\text { CMML } 2\end{array}\end{array}$ & $\begin{array}{c}n=26 \\
21(81 \%) \\
5(19 \%)\end{array}$ & $\begin{array}{l}n=103 \\
96(93 \%) \\
7(7 \%)\end{array}$ & $\begin{array}{l}\text { Fisher } \\
p=0.06\end{array}$ \\
\hline $\begin{array}{l}\text { Karyotype } \\
\text { Good or intermediate } \\
\text { Poor }\end{array}$ & $\begin{array}{c}\mathrm{n}=20 \\
17(85 \%) \\
3(15 \%)\end{array}$ & $\begin{array}{c}n=89 \\
87(98 \%) \\
2(2 \%)\end{array}$ & $\begin{array}{l}\text { Fisher } \\
p=0.04\end{array}$ \\
\hline $\begin{array}{l}\text { CMML-Specific Prognostic Scoring System score } \\
\text { Low } \\
\text { Intermediate1/2 }\end{array}$ & $\begin{array}{c}\mathrm{n}=16 \\
6(37.5 \%)\end{array}$ & $\begin{array}{c}\mathrm{n}=55 \\
28(51 \%)\end{array}$ & $\begin{array}{l}\text { Fisher } \\
p=0.41\end{array}$ \\
\hline
\end{tabular}




\begin{tabular}{|l|c|c|c|}
\hline \multicolumn{1}{|c|}{ High } & $9(56,5 \%)$ & $20(36 \%)$ & \\
& $1(6 \%)$ & $7(13 \%)$ & \\
\hline Acute myeloid leukemia & $\mathrm{n}=23$ & $\mathrm{n}=71$ & Fisher \\
Progression & $6(26 \%)$ & $11(16 \%)$ & $\mathrm{p}=0.17$ \\
Deaths & $4(17 \%)$ & $25(35 \%)$ & $\mathrm{p}=0.23$ \\
\hline Marrow blasts (mean std) & $3.2(4.9)$ & $6.7(6.1)$ & $\mathrm{S}$ Student \\
(min median max) & $0-2-28$ & $0-4-20$ & $\mathrm{p}=0.01$ \\
\hline
\end{tabular}

Table 2. Types of CMML-associated AID.

\begin{tabular}{lcc}
\hline Type & No. (\%) & Type (n) \\
\hline Systemic vasculitis & $14(54 \%)$ & $\begin{array}{c}\text { Polyarteritis nodosa (6) } \\
\text { Giant cell arteritis (3) } \\
\text { Cryoglobulinemia (2) } \\
\text { Behcet’s disease (1) }\end{array}$ \\
& & $\begin{array}{c}\text { Granulomatosis with polyangeitis (2) } \\
\text { Connective tissue diseases }\end{array}$ \\
& $2(8 \%)$ & Sjogren's syndrome (1) \\
\hline Neutrophilic dermatosis & $2(8 \%)$ & Sweet syndrome (2) \\
\hline Inflammatory arthritis & $4(15 \%)$ & $\begin{array}{c}\text { Polymyalgia rheumatica (2) } \\
\text { Undifferentiated (2) }\end{array}$ \\
\hline Unclassified & & - \\
\hline Retroperitoneal fibrosis & $1(3.5 \%)$ & - \\
\hline Immune thrombocytopenia & $1(3.5 \%)$ & - \\
\hline
\end{tabular}


Table 3. CMML-associated SAIDs cases from the literature.

\begin{tabular}{|c|c|c|c|c|c|}
\hline Author & Cases & $\begin{array}{c}\text { MDS } \\
\text { cytogenetics }\end{array}$ & SAID features & SAID treatment & SAID, MDS and general outcome \\
\hline $\begin{array}{c}\text { Smail, } \\
1989\end{array}$ & $1 \mathrm{~F}$ & NA & GPA & CS, Cy & SAID remission, death from AML \\
\hline $\begin{array}{c}\text { Leung, } \\
1986 \\
\end{array}$ & $1 \mathrm{M}$ & NA & PAN & CS, Cy & SAID remission, AML, death from infection \\
\hline $\begin{array}{l}\text { Hamidou, } \\
2001\end{array}$ & $\begin{array}{c}n=8 \\
(6 \mathrm{M} / 2 \mathrm{~F})\end{array}$ & $\begin{array}{c}\text { Del12 } \\
45-46 \text { XX 3p- }\end{array}$ & $\begin{array}{c}\text { PAN }=7 \\
\text { ANCA }(+) \text { vasculitis }\end{array}$ & $\begin{array}{c}\mathrm{CS}=8, \mathrm{Cy}=4, \\
\mathrm{VP} 16=2, \mathrm{MTX}=1, \\
\text { HA }=1\end{array}$ & $\begin{array}{c}1 \text { remission } \\
3 \text { deaths from vasculitis } \\
2 \text { deaths from infection } \\
2 \text { deaths unexplained }\end{array}$ \\
\hline Saif, 2002 & $\begin{array}{c}n=3 \\
(1 \mathrm{M} / 2 \mathrm{~F})\end{array}$ & $\begin{array}{l}5 \mathrm{q}-;+8 \\
1 \mathrm{~N} \\
1 \mathrm{NA}\end{array}$ & $\begin{array}{l}\text { Pyoderma gangrenosum } \\
\text { Vascultis } \\
\text { ITP }\end{array}$ & $\begin{array}{l}\text { CS,Cy, VP16 } \\
\text { CS } \\
\text { CS, IVIg }\end{array}$ & $\begin{array}{l}\text { SAID remission, stable CMML } \\
\text { AID remission, death from cerebral bleeding } \\
\text { ITP transient response, no AML }\end{array}$ \\
\hline $\begin{array}{l}\text { Giannouli, } \\
2004\end{array}$ & $\begin{array}{c}n=2 \\
(1 \mathrm{M} / 1 \mathrm{~F})\end{array}$ & $\begin{array}{c}1 \mathrm{~N} \\
44 X Y ; \text { del7, } \\
\text { del5, del 3q }\end{array}$ & Leucocytoclastic vasculitis & $\mathrm{CS}=1, \mathrm{ATG}=1$ & $\begin{array}{l}\text { Refractory on SAID and MDS, deaths from } \\
\text { infection }\end{array}$ \\
\hline $\begin{array}{c}\text { Isoda, } \\
2009\end{array}$ & $1 \mathrm{~F}$ & $46 \mathrm{XY} \mathrm{t}(3 ; 8)$ & CIDP & IVIg, CS & SAID remission, AML \\
\hline $\begin{array}{l}\text { Park, } \\
2011\end{array}$ & $1 \mathrm{~F}$ & $\mathrm{~N}$ & Large vessel vasculitis & CS, Cy & SAID response, AML, death after alloASCT \\
\hline $\begin{array}{l}\text { Hadjadj, } \\
2014\end{array}$ & $\begin{array}{c}n=8 \\
(5 \mathrm{M} / 3 \mathrm{~F})\end{array}$ & $\begin{array}{c}5 \mathrm{~N} \\
47 \mathrm{XY} ;+21\end{array}$ & ITP & $\begin{array}{c}\text { CS=4, } \\
\text { Romiplostin = } 3 \\
\text { Rituximab }=1 \text {, IVIg } \\
=2\end{array}$ & 7 chronic ITP, no AML, 1 death from infection \\
\hline $\begin{array}{c}\text { Peker, } \\
2015\end{array}$ & $\begin{array}{c}n=24 \\
(18 \mathrm{M} / 6 \mathrm{~F})\end{array}$ & $\begin{array}{c}\text { MLL mutation }=2 \\
\text { monosomy } 7 \\
\text { Trisomy } 8 \\
\text { Del20q }(=2) \\
15 \mathrm{~N}\end{array}$ & $\begin{array}{c}7 \mathrm{ITP}, \text { Gout disease }=6 \\
\text { Psoriasis }=5, \mathrm{RA}=3 \\
\mathrm{MS}=2, \text { Sjogren }=1 \\
\mathrm{IBD}=1, \text { Polymyalgia } \\
\text { rheumatica }=1\end{array}$ & $\begin{array}{c}C S=24 \\
\text { Rituximab }=4\end{array}$ & NA \\
\hline
\end{tabular}

NA: not available, N: normal, CS: corticosteroids, Cy: cyclophosphamide, MTX: methotrexate, IVIg: intravenous immunoglobulin, CIDP: chronic inflammatory demyelinating polyneuropathy, ITP: immunologic thrombocytopenia, RA: rheumatoid arthritis, MS: multiple sclerosis, IBD: inflammatory bowel disease ; AML, acute myeloid leukemia; MDS, myelodysplastic syndrome 
